\title{
Fixed Point Theorem With $C$-Class Functions in Partial Metric Spaces
}

\author{
Jitender Kumar \\ Department of Mathematics \\ Govt. College for Women \\ Jind, Haryana 126102, India
}

\author{
Sachin Vashistha \\ Department of Mathematics \\ Hindu College, University of Delhi \\ Delhi 110007, India
}

\begin{abstract}
The aim of this paper is to prove a fixed point theorem using $C$ class function and $\phi, \psi$ altering distance functions in partial metric spaces.
\end{abstract}

\section{General Terms}

Primary 47H10; Secondary 54H25

\section{Keywords}

Fixed point theorem, coincidence point, metric space, $C$-class function

\section{INTRODUCTION AND MATHEMATICAL PRELIMINARIES}

The concept of partial metric spaces were introduced by Matthews in [10] as a part of the study of denotational semantics of data flow networks. These spaces are generalizations of usual metric spaces where the self distance for any point need not be equal to zero.

Let $X$ be non-empty set and $\rho: X \times X \rightarrow[0, \infty)$ be a function such that for all $x, y, z \in X$ :

(i) $x=y \Leftrightarrow \rho(x, x)=\rho(x, y)=\rho(y, y)$, ( $T_{0}$-separation axiom)

(ii) $\rho(x, x) \leq \rho(x, y)$,

(iii) $\rho(x, y)=\rho(y, x)$, (Symmetry)

(iv) $\rho(x, y) \leq \rho(x, z)+\rho(z, y)-\rho(z, z)$ (Modified Triangular Inequality)

A partial metric space (for Short PMS) is a pair $(X, \rho)$ such that $X$ is a non-empty set and $\rho$ is a partial metric on $X$. It is clear that if $\rho(x, y)=0$, then $x=y$. But if $x=y, \rho(x, y)$ may not be 0 .

THEOREM $1.1[10]$. Let $(X, \rho)$ be a complete partial metric space and let $T: X \rightarrow X$ be a contraction mapping, that is there exists $\lambda \in[0,1)$ such that $\rho(T x, T y) \leq \lambda \rho(x, y)$, for all $x, y \in X$. Then $T$ has a unique filed point $z \in X$. Moreover, $\rho(z, z)=0$.

Later on, Abdelijawad [1], Acar [2], [3], Altun [4], Karapinar and Erhan [14], Oltar and Valero [15] gave some generalizations of the result of Matthews.

THEOREM 1.2. Let $(X, \rho)$ be a complete partial metric space and let $T: X \rightarrow X$ be a map such that
$\rho(T x, T y) \leq \varphi(M(x, y)$, for all $x, y \in X$ where $M(x, y)=$ $\max \{\rho(x, y), \rho(x, T x), \rho(y, T y), 1 / 2[\rho(x, T y)+\rho(y, T x)]\}$ and $\varphi$ satisfies one of the following.

(i) $\varphi:(0, \infty) \rightarrow(0, \infty)$ is an upper semicontinuous from the right such that $\varphi(t)<t$ for all $t>0$ [17].

(ii) $\varphi:(0, \infty) \rightarrow(0, \infty)$ is a non decreasing function such that $\varphi n(t) \rightarrow 0$ as $n \rightarrow \infty$ for all $t>0$ [18].

Then $T$ has a unique fixed point $z \in X$. Moreover, $\rho(z, z)=0$.

On the other hand, Dukic et al. [19] proved the following nice fixed point theorem. Before, we introduce the set $S$ of function $\beta:[0, \infty) \rightarrow[0,1)$ satisfying $\beta\left(t_{n}\right) \rightarrow 1$ implies $t_{n} \rightarrow 0$.

THEOREM 1.3. Let $(X, \rho)$ be a complete partial metric space and let $T: X \rightarrow X$ be a self-map. Suppose that there exists $\beta \in S$ such that

$$
\rho(T x, T y) \leq \beta(\rho(x, y)) \rho(x, y)
$$

holds for all $x, y \in X$. Then $T$ has a unique fixed point $z \in X$ and for each $x \in X$, the Picard sequence $\left\{T^{n} x\right\}$ converges to $z$ when $n \rightarrow \infty$.

THEOREM 1.4 [2]. Let $(X, \rho)$ be a complete partial metric space and let $T: X \rightarrow X$ be a self-map. Suppose that there exist $\beta \in S$ such that

$$
\rho(T x, T y) \leq \beta(M(x, y))
$$

hold for all $x, y \in X$, where

$$
\begin{array}{r}
M(x, y)=\max \{\rho(x, y), \rho(x, T x), \rho(y, T y), \\
1 / 2[\rho(x, T y)+\rho(y, T x)]\} .
\end{array}
$$

Then $T$ has a unique fixed point $z \in X$.

In 2014 the concept of $C$-class functions (see Definition 1) was introduced by A.H. Ansari in [7] that is pivotal result in fixed point theory, for example see number (1), (2) from Example 2.

Definition 1 [20]. A mapping $f:[0, \infty)^{2} \rightarrow R$ is called $C$-class function if it is continuous and satisfies following axioms:

(1) $f(s, t) \leq s$ :

(2) $f(s, t)=s$ implies that either $s=0$ or $t=0$; for all $s, t \in$ $[0, \infty)$.

Note for some $f$ we have that $f(0,0)=0$. 
We denote $C$-class functions as $C$.

EXAMPLE 2 [20]. The following functions $F:[0, \infty)^{2} \rightarrow R$ are elements of $C$, for all $s, t \in[0, \infty)$ :

(1) $F(s, t)=s-t, F(s, t)=s \Rightarrow t=0$.

(2) $F(s, t)=m s, 0<m<1, F(s, t)=s \Rightarrow s=0$;

(3) $F(s, t)=s(1+t) r ; r \in(0, \infty), F(s, t)=s \Rightarrow s=0$ or $t=0$

(4) $F(s, t)=\log \left(t+a^{s}\right) /(1+t), a>1, F(s, t)=s \Rightarrow s=0$ ort $=0$;

(5) $F(s, t)=\ln \left(1+a^{s}\right) / 2, a>e, F(s, t)=s \Rightarrow s=0$;

DeFINITION 3 [21]. A function $\psi:[0, \infty) \rightarrow[0, \infty)$ is called an altering distance function if the following properties are satisfied:

(i) $\psi$ is non-decreasing and continuous,

(ii) $\psi(t)=0$ if and only if $t=0$.

DEFINITION 4. A function $\psi: R \rightarrow R$ is called total altering distance function if the following properties are satisfied:

(i) $\psi$ is non-decreasing and continuous,

(ii) $\psi(t)=0$ if and only if $t=0$.

REMARK 5. We denote $\psi$ inf set total altering distance functions.

DEFINITION 6. An ultra altering distance function is a continuous, nondecreasing mapping $\phi:[0, \infty) \rightarrow[0, \infty)$ such that $\phi(t)>0, t>0$ and $\phi(0)=0$.

REMARK 7. We denote u set ultra altering distance functions.

Definition 8. A tripled $(\psi, \phi, F)$ where $\psi \in \Psi, \phi \in \Phi_{u}$ and $F \in C$ is say to be monotone if for any $x, y \in[0, \infty)$

$$
x \leq y \Rightarrow F(\psi(x), \phi(x)) \leq F(\psi(y), \phi(y)) .
$$

EXAMPLE 9. Let $F(s, t)=s-t, \varphi(x)=\sqrt{x}$

$$
\psi(x)= \begin{cases}x & \text { if } 0 \leq x \leq 1, \\ x^{2} & \text { if } x>1\end{cases}
$$

then $(\psi, \varphi, F)$ is monotone.

EXAMPLE 10. Let $F(s, t)=s-t, \varphi(x)=x^{2}$

$$
\psi(x)= \begin{cases}x & \text { if } 0 \leq x \leq 1, \\ x^{2} & \text { if } x>1\end{cases}
$$

then $(\psi, \varphi, F)$ is not monotone.

LEMMA 11 [22]. If $\left\{x^{n}\right\}$ with $\lim _{n \rightarrow \infty} d\left(x_{n}, x_{n+1}\right)=0$ is not a Cauchy sequence in $(X, p)$, and two sequences $\{m(k)\}$ and $\{n(k)\}$ of positive integers such that $n(k)>m(k)>k$, then the following four sequences

$$
\begin{aligned}
& p\left(x_{m(k)}, x_{n(k)+1}\right), p\left(x_{m(k)}, x_{n(k)}\right), \\
& p\left(x_{m(k)-1}, x_{n(k)+1}\right), p\left(x_{m(k)-1}, x_{n(k)}\right)
\end{aligned}
$$

tend to $\varepsilon>0$, when $k \rightarrow \infty$.

\section{MAIN RESULT}

THEOREM 2.1. $(X, \rho)$ be a complete partial metric space and let $f: X \rightarrow X$ be a self-map. Suppose that there exist $F \in C$ such that

$$
\psi\left(\rho\left(f_{x}, f_{y}\right) \leq F(\psi(M(x, y)), \varphi(M(x, y)))\right.
$$

holds for all $x, y \in X$, where $\psi \in \Psi_{\mathrm{inf}}, \varphi \in \Phi, F \in C$, such that $(\psi, \varphi, F)$ is monotone and

$M(x, y)=\max \left\{\rho(x, y), \rho\left(x, f_{x}\right), \rho\left(y, f_{y}\right), \frac{1}{2}\left[\rho\left(x, f_{y}\right)+\rho\left(y, f_{x}\right)\right]\right\}$

Then $f$ has a unique fixed point $z \in X$.

Proof. Suppose $x_{0}$ is an arbitrary point of $X$ and define the sequence $\left\{x^{n}\right\}$ in $X$ such that

$$
x_{n}=f_{x_{n-1}}=f^{n}\left(x_{0}\right) \quad \text { for every } n \in N .
$$

If $x_{n}=x_{n+1}$ for some $n \in N$, then $x_{n}$ is a fixed point of $f$ and the existence part of the proof is finished. Suppose that $x_{n} \neq x_{n+1}$ for every $n \in N$.

Then by (1), we have

$$
\begin{aligned}
\psi\left(\rho\left(x_{n}, x_{n+1}\right)\right) & =\psi\left(\rho\left(f_{x_{n-1}}, f_{x_{n}}\right)\right) \\
& \leq F\left(\psi \left(M\left(x_{n-1}, x_{n}\right), \varphi\left(M\left(x_{n-1}, x_{n}\right)\right)\right.\right.
\end{aligned}
$$

on the other hand, since

$$
\begin{aligned}
& \frac{1}{2}\left[\rho\left(x_{n-1}, f_{x_{n}}\right)+\rho\left(x_{n}, f_{x_{n-1}}\right)\right] \\
& =\frac{1}{2}\left[\rho\left(x_{n-1}, x_{n+1}\right)+\rho\left(x_{n}, x_{n}\right)\right] \\
& \leq \frac{1}{2}\left[\rho\left(x_{n-1}, x_{n}\right)+\rho\left(x_{n}, x_{n+1}\right)\right] \\
& \leq \max \left\{\rho\left(x_{n-1}, x_{n}\right), \rho\left(x_{n}, x_{n+1}\right)\right\} \\
& =\rho\left(x_{n-1}, x_{n}\right) .
\end{aligned}
$$

Then

$$
\begin{aligned}
& M\left(x_{n-1}, x_{n}\right) \\
& =\max \left\{\rho\left(x_{n-1}, x_{n}\right), \rho\left(x_{n-1}, f_{x_{n-1}}\right), \rho\left(x_{n}, f_{x_{n}}\right),\right. \\
& \left.\quad \frac{1}{2}\left[\rho\left(x_{n-1}, f_{x_{n}}\right)+\rho\left(x_{n}, f_{x_{n-1}}\right)\right]\right\} \\
& =\max \left\{\rho\left(x_{n-1}, x_{n}\right), \rho\left(x_{n-1}, x_{n}\right), \rho\left(x_{n}, x_{n+1}\right),\right. \\
& \left.\quad \frac{1}{2}\left[\rho\left(x_{n-1}, x_{n+1}\right)+\rho\left(x_{n}, x_{n}\right)\right]\right\} \\
& =\rho\left(x_{n-1}, x_{n}\right) .
\end{aligned}
$$

So,

$$
\begin{aligned}
& \psi\left(\rho\left(x_{n}, x_{n+1}\right)\right) \leq F\left(\psi\left(\rho\left(x_{n-1}, x_{n}\right)\right), \varphi\left(\rho\left(x_{n-1}, x_{n}\right)\right)\right) \\
& \leq \psi\left(\rho\left(x_{n-1}, x_{n}\right)\right) \\
& \Rightarrow \quad \rho\left(x_{n}, x_{n+1}\right) \leq \rho\left(x_{n-1}, x_{n}\right) .
\end{aligned}
$$

thus $\left\{\rho\left(x_{n}, x_{n+1}\right)\right\}$ is a non-increasing sequence of non-negative real numbers. Hence $\lim _{n \rightarrow \infty} \rho\left(x_{n}, x_{n+1}\right)=\gamma \geq 0$ for certain $\gamma \in$ $[0, \infty)$. 
Now, we will prove that $\gamma=0$. In the contrary case, from (3) with letting $n \rightarrow \infty$

$$
\psi(r)=F(\psi(r), \varphi(r))
$$

So, $\psi(r)=0$, or $\varphi(r)=0$. Consequently, $r=0$.

This contradicts that $r=0$.

Therefore, $\lim _{n \rightarrow \infty} \rho\left(x_{n}, x_{n+1}\right)=0$.

Now, we show that $\left\{x^{n}\right\}$ is a Cauchy sequence in $X$ i.e.

We prove that $\lim _{n, m \rightarrow \infty} \rho\left(x_{n}, x_{m}\right)=0$.

In the contrary, we suppose that the sequence $\left\{x^{n}\right\}$ is not a Cauchy sequence in $(X, \rho)$, then sequences in Lemma 11 tend to $\varepsilon>0$, when $k \rightarrow \infty$.

So we can see that

$$
\lim _{k \rightarrow \infty} M\left(x_{m(k)}, x_{n(k)}\right)=\varepsilon .
$$

So from 1

$$
\begin{aligned}
\psi\left(\rho\left(x_{m(k)}, x_{n(k)}\right)\right) & =\psi\left(\rho\left(f_{x_{m(k)-1}}, f_{x_{n(k)-1}}\right)\right) \\
\leq & F\left(\psi\left(M\left(x_{m(k)-1}, x_{n(k)-1}\right)\right),\right. \\
& \left.\varphi\left(M\left(x_{m(k)-1}, x_{n(k)-1}\right)\right)\right)
\end{aligned}
$$

with letting $k \rightarrow \infty$,

$$
\psi(\varepsilon) \leq F(\psi(\varepsilon), \varphi(\varepsilon))
$$

So, $\psi(\varepsilon)=0$, or $\varphi(\varepsilon)=0$.

Consequently, $\varepsilon=0$, this contradicts our assumption that

$$
\lim _{n, m \rightarrow \infty} \rho\left(x_{n}, x_{m}\right)=\varepsilon>0 .
$$

Therefore,

$$
\lim _{n, m \rightarrow \infty} \rho\left(x_{n}, x_{m}\right)=0 .
$$

This means that $\left\{x^{n}\right\}$ is a Cauchy sequence in a complete partial metric space $(X, \rho)$ and consequently, there exists $z \in X$ such that

$$
0=\lim _{n, m \rightarrow \infty} \rho\left(x_{n}, x_{m}\right)=\lim _{n \rightarrow \infty} \rho\left(x_{n}, z\right)=\rho(z, z) .
$$

Now, we will prove that $z$ is a fixed point of $f$. For this assume $\rho\left(z, f_{z}\right)>0$.

Then, we have

$$
\rho\left(z, f_{z}\right) \leq \rho\left(z, f_{x_{n}}\right)+\rho\left(f_{x_{n}}, f_{z}\right)-\rho\left(f_{x_{n}}, f_{x_{n}}\right),
$$

This implies that

$$
\begin{aligned}
& \psi\left(\rho\left(z, f_{z}\right)-\rho\left(z, f_{x_{n}}\right)+\rho\left(f_{x_{n}}, f_{x_{n}}\right)\right) \\
& \quad \leq \psi\left(\rho\left(f_{x_{n}}, f_{z}\right)\right) \\
& \quad \leq F\left(\psi\left(M\left(x_{n}, z\right)\right), \varphi\left(M\left(x_{n}, z\right)\right)\right)
\end{aligned}
$$

where

$$
\begin{aligned}
& M\left(x_{n}, z\right)=\max \left\{\rho\left(x_{n}, z\right), \rho\left(x_{n}, f_{x_{n}}\right), \rho\left(z, f_{z}\right),\right.\left.\frac{1}{2}\left[\rho\left(x_{n}, f_{z}\right)+\rho\left(z, f_{x_{n}}\right)\right]\right\} \\
&=\max \left\{\rho\left(x_{n}, z\right), \rho\left(x_{n}, x_{n+1}\right), \rho\left(z, f_{z}\right),\right. \\
& \\
&\left.\quad \frac{1}{2}\left[\rho\left(x_{n}, f_{z}\right)+\rho\left(z, x_{n+1}\right)\right]\right\} \\
&=\max \{\rho(z, z), \rho(z, z), \\
&\left.\rho\left(z, f_{z}\right),\left[\rho\left(z, f_{z}\right)+\rho(z, z)\right] / 2\right\} \\
&=\rho\left(z, f_{z}\right) .
\end{aligned}
$$

And so with letting $n \rightarrow \infty$

$$
\psi\left(\rho\left(z, f_{z}\right)\right) \leq F\left(\psi\left(\rho\left(z, f_{z}\right)\right), \varphi\left(\rho\left(z, f_{z}\right)\right)\right)
$$

So, $\psi\left(\rho\left(z, f_{z}\right)\right)=0$, or $\varphi\left(\rho\left(z, f_{z}\right)\right)=0$.

Consequently, $\rho\left(z, f_{z}\right)=0$, this contradicts the inequality $\rho\left(z, f_{z}\right)>0$, so that $\rho\left(z, f_{z}\right)=0$. Thus $z=f_{z}$.

Suppose that $z$ and $w$ are fixed points of $f$ then, if $z \neq w$, we have by (1)

$$
\begin{aligned}
\psi(\rho(z, w)) & =\psi\left(\rho\left(f_{z}, f w\right)\right) \\
& \leq F(\psi(M(z, w)), \varphi(M(z, w)))
\end{aligned}
$$

where

$$
\begin{aligned}
& M(z, w)=\max \left\{\rho(z, w), \rho\left(z, f_{z}\right), \rho(w, f w),\right.\left.\frac{1}{2}\left[\rho(z, f w)+\rho\left(w, f_{z}\right)\right]\right\} \\
&= \max \{\rho(z, w), \rho(z, z), \rho(w, w), \\
&\left.\frac{1}{2}[\rho(z, w)+\rho(w, z)]\right\} \\
&=\rho(z, w)
\end{aligned}
$$

Thus

$$
\psi(\rho(z, w)) \leq F(\psi(\rho(z, w)), \varphi(\rho(z, w)))
$$

So, $\psi(\rho(z, w))=0$, or $\varphi(\rho(z, w))=0$.

Consequently, $\rho(z, w)=0$, a contradiction.

This proves the uniqueness of the fixed point of $f$.

\section{EXAMPLE}

Let $X=[0,1]$ and $\rho(x, y)=\max \{x, y\}$. Then $(X, \rho)$ is a complete partial metric space.

Let $F(s, t)=m . s, 0<m<1$

$$
\begin{array}{rlrl}
\phi(x) & =\sqrt{x}, & & x \in[0,1] \\
\psi(x) & =x, & x \in[0,1] \\
f(x) & =\frac{x^{2}}{2}, & & x \in[0,1] .
\end{array}
$$

Clearly, $F$ is a $C$-class function.

$(\psi, \phi, F)$ is a monotone function. 
All the conditions of Theorem 2.1 are satisfied. ' 0 ' is the unique fixed point of $f$.

\section{REFERENCES}

[1] T. Abdeljawad, E. Karapinar and K. Tas: Existence and uniqueness of a common fixed point on partial metric spaces, Appl. Math. Lett, 24 (2011), 1900-1904.

[2] O. Acar and I. Altun: Some generalization of Caristi type fixed point theorem on partial metric spaces, Filomat 26 (4) (2012), 833-837.

[3] O. Acar, I. Altun and S. Romaguera: Caristi's type mapping in complete partial metric space, Fixed Point Theory (CuljNapoca), (to appear).

[4] I. Altun and O. Acar: Fixed point theorems for weak contractions in the sense of Berinde on partial metric spaces, Topol. Appl., 159 (2012), 2642-2648.

[5] S. Cobzas: Completeness in quasi-metric spaces and Ekeland Variational Principle, Topol. Appl., 158 (2011), 1073-1084.

[6] M. H. Escardo: Pcf Extended with real numbers, Theor. Comput. Sci., 162 (1996), 79-115.

[7] M. Geraghty: On contractive mappings, Proc. Am. Math. Soc., 40 (1973), 604-608.

[8] R. Heckmann: Approximation of metric spaces by partial metric space, Appl. Categ. Struct., 7 (1999), 71-83.

[9] D. Ilic, V. Pavlovic and V. Rakocevic: Some new extensions of Banach's contraction principle to partial metric space, Appl. Math. Lett., 24 (2011), 1326-1330.

[10] S. G. Mattews: Partial metric topology, Proc. 8th Summer Conference on General Topology and Applications, Ann. New York Acad. Sci., 728 (1994), 183-197.

[11] S. Romaguera: A Kirk type characterization of completeness for partial metric spaces, Fixed Point Theory and applications. Article ID 493298, (2010).

[12] I. Altun and K. Sadaragani: Generalized Geraghty type mapping on partial metric spaces and fixed Point results, Arab. J. Math. (2013), 247-253.

[13] I. Altun, D. Trkolu and B. E. Rhoades: Fixed points of weakly compatible maps satisfying a general contractive condition of integral type, Fixed Point Theory and Applications, 2007 (2007), article ID 17301, 9 pages.

[14] E. Karapinar and I. M. Erhan: Fixed point theorem for operators on partial metric spaces, Appl. Math. Lett., 24 (2011), 1894-1899.

[15] S. Oltar and O. Valero: Banach's fixed point theorem for partial metric spaces, Rend. Istit. Math. Univ. Trieste., 36 (2004), 17-26.

[16] O. Valero: On Banach fixed point theorems for partial spaces, Appl. General Topol., 6 (2005), 229-240.

[17] S. Romaguera: Fixed point theorems for generalized contractions on partial metric spaces, Topol. Appl., 218 (2011), 2398-2406.

[18] S Romaguera: Matkowski's type theorems for generalized contractions on (ordered) partial metric spaces, Appl. General Topol., 12 (2011), 213-220.

[19] D. Dukic, Z. Kadelburg and S. Radenovic: Fixed points of Geraghty type mapping in various generalized metric spaces, Abstract and Applied Analysis, 2011 (2011), article ID 561245, p. 13.
[20] A. H. Ansari, Note on " $\phi-\psi$ contractive type mappings and related fixed point", The 2nd Regional Conference on Mathematics And Applications, PNU, September 2014, pp. 377380.

[21] M.S. Khan, M. Swaleh and S. Sessa, Fixed point theorems by altering distances between the points, Bulletin of the Australian Mathematical Society, 30 (1) (1984), 1-9.

[22] A. S. Saluja, M. S. Khan, P. K. Jhade and B. Fisher: Some fixed point theorems for mapping involving rational type expressions in partial metric spaces, Applied Mathematics ENotes, 15 (2015), 147-161. 